\title{
Psicoanálisis y Ciencia: \\ Una aproximación al estudio de su relación a partir de Jacques Lacan
}

\author{
Psychoanalysis and Science: \\ An approximation to the study of their \\ relationship from Jacques Lacan
}

\author{
GONZALO GRAU PÉREZ \\ Universidad de la República, Uruguay
}

Recibido:24/09/16 Aceptado:10/10/16

\section{RESUMEN}

El problema de la relación del psicoanálisis con la ciencia ha sido ampliamente debatido desde los orígenes mismos del psicoanálisis. Este trabajo aborda el problema a partir de la obra de Jacques Lacan. Se parte de que la pregunta «ies el psicoanálisis una ciencia?» es insuficiente; es necesario plantear el problema desde otra perspectiva. Lacan propone una forma novedosa de abordar la relación del psicoanálisis y la ciencia, a partir de la dimensión del sujeto, el saber y la verdad.

\section{PALABRAS CLAVE}

LACAN; CIENCIA; PSICOANÁLISIS; EPISTEMOLOGÍA

\begin{abstract}
ABSTACT
The issue of the relationship between psychoanalysis and science has been widely debated since the origins of psychoanalysis. This paper approaches the issue from Jacques Lacan's work.
\end{abstract}


The question «Is psychoanalysis a science?» is insufficient and is necessary consider the problem from another perspective. Lacan proposes a novel way to approaching the relationship between psychoanalysis and science, from the dimension of the subject, knowledge and truth.

KEYWORDS:

LACAN; SCIENCE; PSYCHOANALYSIS; EPISTEMOLOGY

«...la ciencia es animada por algún misterioso deseo, pero ella, al igual que el inconsciente, tampoco sabe qué quiere decir ese deseo. El porvenir nos lo revelará y quizá del lado de (...) aquellos que no vacilaron en escribir con sus esfuerzos, incluso con su sangre, el libro de la ciencia occidental...»

J. Lacan, 1960 (p.386)

\section{UNA TEORÍA DE LA CIENCIA EN LACAN}

LA CUESTIÓN DE LA RELACIÓN DEL PSICOANÁLISIS CON LA CIENCIA tiene un lugar privilegiado en el pensamiento de Lacan, ya que fue abordada de forma repetida e insistente a lo largo de su obra. Milner plantea que existe una teoría de la ciencia en Lacan (1996, p.37), que puede ser leída, incluso, como «un verdadero doctrinal de la ciencia» (Ibídem, p.45). Se intentará una aproximación al mismo, sobre todo a algunos de sus aspectos centrales y particularmente, a los puntos donde se establece la frontera entre el psicoanálisis y la ciencia.

Una pregunta inicial podría ser si el psicoanálisis, para Lacan, podría llegar a ser una ciencia (en el sentido moderno). Aquí es conveniente resistir la tentación de apresurarse a contestar negativamente, para poder avanzar en el desarrollo teórico del problema.

Se puede comenzar mencionando una famosa, y en apariencia paradójica, afirmación de Lacan: «el sujeto sobre el que operamos en psicoanálisis no puede ser sino el sujeto de la ciencia» (2002a, p.816). ${ }^{1}$ Según Milner (op. cit., p.35), este enunciado afirma tres cosas. En primer lugar que el psicoanálisis opera sobre un sujeto y no sobre un «yo». Segundo, que hay un sujeto de la ciencia, y por último que el sujeto de la ciencia y el del psicoanálisis hacen uno. Pero hay que tener en cuenta que al decir esto, Lacan no está afirmando que el psicoanálisis sea una ciencia, ya que al decir que el sujeto del psicoanálisis es el sujeto de la ciencia, se explicita la distancia, o la diferencia, entre psicoanálisis y ciencia. Cuando habla del sujeto de la ciencia, Lacan se está refiriendo al sujeto cartesia-

1 «Sujeto» en francés (sujet) incluye, en sus acepciones, tema, materia, asunto. De modo que una de las posibles lecturas de esta «formula» lacaniana podría ser: «el asunto sobre el que operamos en psicoanálisis no puede ser sino el asunto de la ciencia». 
no, y esto es porque «El saber científico (...) está ligado por naturaleza al sujeto cartesiano» (Le Gaufey 2012, p.20). A continuación se desarrolla este punto.

\section{EL SUJETO CARTESIANO EXAMINADO POR LACAN}

El sujeto cartesiano, que refleja la unidad del saber, es un sujeto sin cualidades que solo depende de su propio acto de pensamiento (Ibídem, p.48). El cogito cartesiano presentado bajo la forma «pienso, luego soy» (Descartes 2004a, p.51) da cuenta de ello. Según Lacan:

«[en] la prueba de escribir: pienso: 'luego soy', con comillas alrededor de la segunda cláusula, se lee que el pensamiento no funda el ser sino anudándose en la palabra donde toda operación toca a la esencia del lenguaje» (2002a, p.821).

Es decir que el ser, como tal, sería producto de una operación de lenguaje; «frente a la ontología, la tesis sofística y la tesis lacaniana forman una unidad: el ser es un efecto de decir» (Cassin 2013, p.57).

A partir del cogito se puede constituir una estructura mínima, una cadena de dos significantes: «pienso» (S1) y «luego soy» (S2), de forma que la enunciación estaría concentrada en «un significante unitario y segundo» (Milner op. cit., p.120), que es «luego soy», y «se plantea, por retroacción, un significante primero» (Ibídem), que es el «yo pienso». Según Milner «el sujeto real insiste en la oscilación (del segundo al primero, del primero al segundo) de estos dos significantes» (Ibídem).

Lacan define al sujeto como aquello que está representado por un significante para otro significante (1987,p.206), por lo que son necesarios dos significantes para producir un sujeto. El sujeto sería, entonces, aquello que emerge entre dos significantes. En el cogito cartesiano el sujeto aparecería entre el «pienso»y el «soy». En esa oscilación, en esa intermitencia entre esos dos significantes, es que a Descartes se le presenta un problema; la evanescencia radical del sujeto. Su existencia depende de la temporalidad del propio acto de enunciación (Dunker 2011, p.294); «Yo soy, existo, esto es cierto; pero, ¿Cuánto tiempo?» (Descartes 2004b, p.126). Mientras el sujeto no está enunciando su existencia, entonces no existe, o por lo menos no puede estar seguro de ella. Por lo tanto, el sujeto cartesiano solo aparecería en el momento en que se representa a sí mismo como existente, como objeto pensado, pero en ese momento es objeto, y desaparece como sujeto.

Descartes se ve obligado entonces, en su tercera meditación, a demostrar la existencia de un Dios no engañador como necesaria (Dunker op. cit., p.294). Dios aquí no es tanto una necesidad teológica, sino más bien una necesidad epistemológica (Le Gaufey 2012, p.30). Este Dios no engañador garantiza la existencia del sujeto a lo largo del tiempo, más allá de su acto de enunciación, 
porque garantiza en última instancia la verdad del saber obtenido por el Ego (el sujeto de Descartes). Hace que las figuras que el Ego se da, representen algo (Ibídem, p.171), que el saber producido del cogito sea un saber verdadero y perdurable, independiente del acto de enunciación.

\section{Un OtRo QUe ENGAÑa Y UN OtRo QUE NO ENGAÑa}

La noción de gran Otro ocupa en la obra de Lacan un lugar, hasta cierto punto, homólogo al Dios de Descartes. Pero sí bien es legitimo plantear que Lacan es cartesiano en cuanto al proceso de constitución del sujeto, es decir el cogito, es sin embargo anticartesiano en cuanto al estatuto de Dios, es decir del Otro (Dunker op. cit, p.295), ya que el Otro lacaniano puede engañar (Lacan 2011c, p.362) , y de la misma forma, puede ser engañado (Lacan 1987, p.45). ${ }^{2}$

Lacan parte de que el sujeto hablante es un sujeto que puede mentir, y cada uno que se tome por sujeto le da entonces a «otros sujetos» la capacidad de mentir, es decir, de no confundirse con la significación de sus enunciados (Le Gaufey 2012, p.180). ${ }^{3}$ En este sentido «No se trata de saber si hablo de mí mismo de manera conforme con lo que soy, sino si cuando hablo de mí, soy el mismo de aquel del que hablo» (Lacan 2002b, p.484), lo que significa una división entre sujeto del enunciado y sujeto de la enunciación. ${ }^{4}$ Esta división, se puede leer en el enunciado lacaniano: «pienso donde no soy, luego soy donde no pienso» (Ibídem), que significa que «no soy allí donde soy juguete de mi pensamiento; pienso en lo que soy, allí donde no pienso pensar» (Ibídem). Por esta división, entre sujeto del enunciado y sujeto de la enunciación, es que el Otro puede engañar, y nunca se puede saber si no nos está engañando, y de la misma forma, puede ser engañado.

2 Ya que «Dios» puede ser engañado, la verdadera formula del ateísmo no sería «Dios ha muerto», sino, «Dios es inconsciente» (Lacan 1987, p.67).

3 Se abre aquí la distancia entre sentido y significado. Eidelsztein explica, a partir de Lacan, que el significado es lo que se dice, mientras que el sentido apunta a la pregunta sobre lo que se quiere decir más allá de lo que se dice: «esto es lo que me dices, pero ¿qué es lo que me quieres decir?»,lo que no supone necesariamente que el Otro lo sepa (2015, p.121). A modo de ejemplo, se puede mencionar el famoso chiste que comenta Freud, muy trabajado por Lacan: «Mentiroso, ¿Por qué me mientes diciendo que vas a Cracovia para que yo piense que vas a Lemberg cuando en realidad vas a Cracovia?».

4 Un ejemplo donde se evidencia esta división es la famosa paradoja del mentiroso. Lacan muestra como la aparente «antinomia de la razón» en el enunciado «yo miento» no es tal. Se trata de un enunciado totalmente válido, ya que «el yo (je) que enuncia, el yo (je) de la enunciación, no es el mismo que el yo (je) del enunciado» (Lacan 1987, p.145). Por un lado estaría el sujeto del enunciado (el mentiroso) y por otro el sujeto de la enunciación, que habla del mentiroso, pero no coincide con él. Esto solo es posible por el hecho de que el sujeto de la enunciación es exterior al enunciado. El decir es exterior al dicho, le ex-siste (Lacan 2012a, p.476): «el decir queda olvidado detrás del dicho» (Ibídem, p.474). 
Esta vinculación estructural entre el «engaño» y el Otro es consecuencia de que, desde la perspectiva lacaniana, «no hay Otro del Otro» (Lacan 2011c, p.98), que equivale a decir que «no hay metalenguaje» (Lacan 1999, p.79), o que «ningún lenguaje podría decir lo verdadero sobre lo verdadero» (Lacan 2002a, p.824). No hay Otro del Otro porque «El sujeto encuentra una falta en el Otro» (Lacan 1987, p.222). El sujeto busca en este Otro aquel significante que lo pueda representar a sí mismo como sujeto, que puede representar su ser, pero el Otro «se encuentra en la estricta imposibilidad de brindar un significante semejante. Está desprovisto de él» (Le Gaufey 2010, p.17). El Otro lacaniano, en tanto lugar de lo simbólico, tiene un límite. Por su propia estructura es intrínsecamente incompleto. Algo allí siempre va a venir a faltar. Esta incompletud es homóloga a la demostrada en los teoremas de incompletitud de Gödel. ${ }^{5}$

En Descartes, lo que le da la unidad al sujeto, lo que lo salva de la evanescencia constante, de su dependencia total del lenguaje, es la garantía del Dios no engañador, del Dios perfecto, y por lo tanto completo. Pero con Lacan esta garantía última se pierde, y con ella la unidad y completitud del saber, así como la indivisión del sujeto. No existe en el Otro un significante que represente al ser del sujeto, ya que el sujeto es justamente lo que está entre dos significantes. Por lo tanto no hay identidad del sujeto, como tampoco hay una identidad del significante, ya que éste no es igual a sí mismo, sino que está siempre en relación a otro significante, y la relación con éste es de pura diferencia.

\section{El PSICOANÁLISIS COMO SINCRÓNICO A LA CIENCIA MODERNA}

Lacan plantea que «es impensable que el psicoanálisis como practica, que el inconsciente, el de Freud, como descubrimiento, hubiesen tenido lugar antes del nacimiento (...) de la ciencia» (Lacan 2002a, pp. 814-815). Esto está relacionado con la afirmación de Milner, de que «el psicoanálisis (...) es intrínsecamente sincrónico con la ciencia moderna» (op. cit., p.155). Para Julien «resulta claro que el nacimiento del psicoanálisis en tal o cual cultura sólo es posible en la modernidad» (op cit.,p.35). El psicoanálisis es contingente, surge

5 El primero de estos teoremas enuncia que cualquier sistema axiomático de la aritmética que sea consistente, contiene proposiciones indecidibles, es decir que es incompleto. Esto significa que se puede construir, en determinado sistema aritmético, una proposición verdadera y a la vez indemostrable en ese sistema (Amster 2010, p.108). El segundo teorema enuncia que ningún sistema poderoso cómo la aritmética es capaz de probar su propia consistencia, dentro de ese sistema (Ibídem, p.122). Este segundo teorema no hace referencia al problema de la incompletitud, sino de la garantía. No se puede encontrar la garantía de la consistencia de un sistema en el interior del mismo, lo que equivale a decir que «no hay verdad de la verdad», o que la verdad, sólo medio-dicha sea (Lacan, 2012a, p.478). En definitiva, solo es posible decidir sobre una proposición indecidible y sobre la garantía de un sistema, desde su exterior, desde otro sistema (que a su vez es incompleto y no demuestra su propia consistencia). 
en determinado momento, y en la actualidad, junto al innegable avance de la ciencia sigue existiendo y operando. Esto solo se explica si se recuerda que el psicoanálisis opera con el propio sujeto de la ciencia. La propia ciencia produce el sujeto con el que el psicoanálisis ejerce su práctica. De esta forma, el psicoanálisis existiría solo porque la ciencia, por su propia estructura, produce un sujeto que le es antinómico, que no puede escribir en su formalización. No puede matematizar al sujeto, porque para trasmitir la escritura formalizada necesita del lenguaje natural (y el lenguaje natural no puede evitar la división entre enunciado y enunciación). Con esto se deduce que si la ciencia desapareciera, con ella también desaparecería el psicoanálisis. Lacan comenta en su seminario titulado «El sinthome» que «El análisis se difunde debido a que pone en tela de juicio la ciencia como tal - ciencia que hace de un objeto un sujeto, cuando el sujeto está, en sí mismo, dividido» (p.37). Según Lacan, a diferencia de la ciencia, el psicoanálisis se difundiría justamente por la restitución del sujeto como tal, es decir, del sujeto en su división (Ibídem).

\section{V. ¿FORCLUSIÓN DEL SUJETO O FORCLUSIÓN DE LA VERDAD?}

Dunker (op. cit.,p.314) plantea que el punto de partida de Descartes, lleva a una elección forzada: o se elige el método, o se elige el sujeto. Si se elige el método, se debe transformar al sujeto en un objeto de conocimiento como cualquier otro, posible de ser representado, cifrado, y por lo tanto se pierde al sujeto mismo, ya que el sujeto de Descartes, Ego, «mantiene su certidumbre excluyéndose absolutamente de la finta constitutiva de toda representación» (Le Gaufey 2012, p.50). Por tanto «No existe figura asignable al ego» (Ibídem). Si se elige al sujeto en cambio, se debe renunciar al método, y con él a toda pretensión de cientificidad (Dunker op cit., p.314). Es clara aquí la elección de la ciencia moderna, y el camino que toma a partir de Descartes, ya que la ciencia se define por una confianza en el método (Ibídem). Esto lleva a pensar que la elección de la ciencia en este punto tiene una consecuencia inevitable: la «forclusión» del sujeto. Para esclarecer esta noción es necesario detenerse en el término tomado por Lacan.

Forclusión es la traducción que Lacan hace de la palabra alemana Verwerfung, utilizada por Freud para nombrar un mecanismo aparentemente similar, pero en esencia distinto, a la represión. Según Lacan, lo forcluído sería aquello que no ha podido inscribirse en el registro simbólico, aquello rechazado, repudiado, expulsado (2011c, p.217). Por su propia estructura, la ciencia necesitaría excluir al sujeto. Ahora bien, «todo lo rehusado en el orden simbólico, en el sentido de la Verwerfung, reaparece en lo real» (Ibídem, p.24) Esto significa que el éxito de la ciencia en esta tarea es siempre parcial, porque el sujeto regresa como una respuesta de lo real, reaparece en lo que está fuera del cálculo, en lo no predecible, lo no esperable, en lo que no estaba dentro de las posibilidades 
de que ocurriera, en palabras de Lacan: «la ciencia se muestra definida por el no-éxito del esfuerzo para suturarlo [al sujeto]» (2002a, p.818). El sujeto aparecería así en los límites de la teorización, en las anomalías, en los obstáculos a la formalización, en las crisis científicas de Kuhn, en lo imposible.

Ahora bien, es necesario plantear otra perspectiva en relación a la posición del sujeto en la ciencia (también elaborada a partir de Lacan), que pone el acento en la forlcusión de la verdad cómo causa, y no en la forclusión del sujeto (Amigo 2009, p.88; Eidelsztein 2012, p.19; Porge 2007, p.99).

Eidelsztein plantea, siguiendo a Lacan, que «la ciencia forcluye a la verdad del seno de su saber y el psicoanálisis la restituye» (2012, p.19). Pero lo fundamental es que la restituye en el propio campo de la ciencia, y no por fuera de él. Cómo dice Lacan, «Freud, (...) supo dejar, bajo el nombre de inconsciente, a la verdad hablar» (2002a, p.824), y en este punto es fundamental tener presente que Freud provenía, en tanto médico, del campo de la ciencia. De esta forma Eidelsztein plantea, a partir de Lacan, que lo que diferenciaría la ciencia del psicoanálisis no es la forclusión del sujeto, sino el rechazo de la función de la verdad como causa. Esta perspectiva es coherente con el decir de Lacan:

«La verdad como causa, ¿ustedes, psicoanalistas, se negarán a asumir su cuestión, cuando es de allí de donde se levantó su carrera? Si hay practicantes para quienes la verdad como tal se supone que actúa, ¿no son precisamente ustedes?» (2002a, p.825).

A diferencia del psicoanálisis, la ciencia se sostendría por el hecho de que «de la verdad como causa no querría-saber-nada» (Ibídem, p.830). La ciencia renuncia a la verdad para producir un tipo de conocimiento inacabado y trasmisible, vacío de contenido normativo (Dunker op. cit.,p.317). Para el psicoanálisis, en cambio, la posición de verdad importa (Ibídem).

La afirmación de Lacan, de que el sujeto del psicoanálisis no es sino el sujeto de la ciencia, implica necesariamente que el sujeto no puede estar forcluido en la ciencia, ya que es la propia ciencia la que produce el sujeto con el que opera el psicoanálisis. Es decir que el sujeto, en el psicoanálisis, es sujeto de ciencia. ${ }^{6}$ Ahora bien, esto no impide que este sujeto producido por la ciencia le sea estructuralmente antinómico: «el sujeto en cuestión sigue siendo el correlato de la ciencia, pero un correlato antinómico puesto que la ciencia se muestra definida por el no-éxito del esfuerzo para suturarlo» (Lacan 2002a, p.818). La antinomia aparece cuando se comprueba que la ciencia se definiría

6 «El científico que hace la ciencia es sin duda un sujeto el también» (Lacan 2002c, p.755). Para Lacan, el sujeto de la ciencia sabe lo que hace, pero no sabe lo que en los efectos de la ciencia interesa a todo el mundo (Ibídem, p.756). Se podría decir que el sujeto de la ciencia no sabe lo que hace cuando hace ciencia, no sabe que «deseo» lo anima (Lacan 1992, p.386). 
en su esfuerzo de excluir al sujeto, de suturar su división, y al mismo tiempo, éste no sería sino su producto. En este punto es necesario «corregir» algunas de las afirmaciones anteriores. Lo que en la ciencia reaparece como respuesta de lo real, a partir de lo que está fuera del cálculo, en lo impredecible, en lo no esperable, es la verdad, y no el sujeto, o si se prefiere, la verdad del sujeto.

\section{LO REAL EN EL PSICOANÁLISIS Y EN LA CIENCIA}

Milner plantea que «La doctrina lacaniana de la ciencia deriva de Koyré, al que utiliza empero para fines que le son ajenos» (op. cit., p.9). Lacan plantea, siguiendo a Koyré, que la ciencia moderna surge con la matematización de lo real. De esta forma se comienza, con Galileo, a «instaurar una física matematizada porque se parte de una formalización simbólica pura» (Lacan 2011d, p.433). Esto «no se consiguió hasta que se tomó la decisión de empezar separando lo simbólico de lo real» (Ibídem). En este sentido, la ciencia moderna desatendería todas las cualidades sensibles del objeto en pos de una escritura puramente simbólica. ${ }^{7}$ Lo real debe escribirse en lenguaje matemático, es decir, en una relación de letras vaciadas de sentido (Lacan 2012a, pp. 501-502). Se trata, antes que nada, de una práctica de escritura rigurosa (Guitart 2003); como comenta Lacan, «en la ciencia la escritura hizo maravillas» (2011a, p.115).

Para Koyré no es la experimentación, sino la formalización matemática, lo que determina al objeto en su estatuto de cientificidad: «La buena física se hace a priori. La teoría precede al hecho» (Koyré 2007, p.194). ${ }^{8}$ Dunker, para ejemplificar esto, comenta que los trabajos de Galileo y de Newton no surgen por la acumulación de datos empíricos que generan un nuevo conocimiento, sino que es la propia formalización matemática que anticipa al objeto o al fenómeno como tal (op. cit, p.315). De esta forma la experimentación debe verificar solo posteriormente la validez de la formalización..$^{9}$ «El objeto científico (...), es un objeto construido, que no debe su emergencia a un simple recorte sensible» (Le Gaufey 2012,p.54). En este punto, existiría una coincidencia fundamental entre la forma de proceder de la ciencia moderna y el psicoanálisis, ya según Lacan:

7 La posición de Lacan, es «antiempirista»: «la condiciones de una ciencia no podrían ser el empirismo» (Lacan 2002c, p.756).

8 Esta posición, "anti-empirista" y "anti-inductivista" es compartida por muchos epistemólogos, entre ellos Kuhn (2013, pp.139-140), Popper (2008, p.49) y Bachelard (1991, pp.15-16).

9 Einstein pensaba de esta forma cuando decía que «Un concepto que sirva para el razonamiento matemático puede relacionarse estrechamente con lo experimental, pero nunca puede deducirse de esto último» (2005, p.117). Ejemplo paradigmático de la anticipación matemática del fenómeno es la propia teoría de la relatividad de Einstein, que es publicada por él en 1905 , y recién comprobada experimentalmente años después. 
«La formalización matemática es nuestra meta, nuestro ideal. ¿Por qué? porque solo ella es matema, es decir, trasmisible íntegramente. La formalización matemática es escritura, pero que no subiste sino empleo para presentarla la lengua que uso» (2011b, p.144).

Lacan sigue el designio de la ciencia moderna: «Sólo la matematización alcanza un real - y por ello es compatible con nuestro discurso, el discurso analítico - un real que no tiene nada que ver con aquello de lo cual ha sido soporte en el conocimiento tradicional» (Ibídem, p.158). Ahora bien, que la formalización matemática sea lo único que alcanza un real y que a su vez sea lo único que se puede trasmitir, no implica una posición de metalenguaje, justamente porque «ninguna formalización de la lengua es trasmisible sin el uso de la lengua misma» (Ibídem,p.144). En este punto, se puede decir que la ciencia y el psicoanálisis no comparten únicamente el sujeto, sino también el estatuto del Otro. Tanto en la ciencia como en el psicoanálisis el Otro es incompleto, y no garantiza la verdad de la verdad. ${ }^{10}$ Ahora bien, hay que realizar una precisión. La ciencia también opera por la vía de la acumulación de saber — por ejemplo, en los períodos que Kuhn denominó "ciencia normal” (2013, p.236) - , y esto solo es posible si se supone cierta garantía de la verdad del saber (Porge op . cit., pp.98-99). Se puede mencionar aquí, a modo de ejemplo, la necesidad del Dios no engañador de Descartes (para garantizar la verdad del cogito), así como del Dios de Newton (para garantizar el espacio y el tiempo absolutos) y el Dios de Einstein (para garantizar el determinismo, a partir de su famosa frase «Dios no juega los dados»). Sin embargo, esta pretensión de garantía es posterior al momento de «hacer ciencia». La prueba es que la ciencia, en su desarrollo, no solo se apoya en el saber previo, sino que refuta y derriba teorías, enunciados y conjeturas precedentes. La estructura de las "revoluciones científicas", tal como la describe Kuhn, muestra una discontinuidad radical en el desarrollo de la ciencia, y una ausencia de garantía definitiva de la verdad del sabe.

En determinado momento de su teorización, Lacan delimita lo real cómo lo imposible lógico: «Para definir este real (...) intenté acotarlo a partir de lo imposible de una modalidad lógica» (2010, p.82), «es con la lógica con lo que este discurso [psicoanalítico] toca lo real, al encontrarlo como imposible, por lo cual es ese discurso [el de la lógica] el que la lleva a su ultima potencia: cien-

10 A modo de ejemplo, el «dispositivo de refutabilidad» de Popper, indica que un enunciado científico debe poder ser refutable, y por lo tanto, ningún experimento u observación empírica puede garantizar la «verdad verdadera» de tal enunciado - siempre puede aparecer algo que lo refute- - Es decir que no es posible realizar una decisión definitiva sobre la verdad o falsedad de un enunciado científico: «quienquiera que plantee un sistema de enunciados absolutamente ciertos, irrevocablemente verdaderos, como finalidad de la ciencia, es seguro que rechazará las propuestas que voy a hacer aquí» (Popper 2008, p.46). 
cia, he dicho, de lo real» (2012a, p.474). Lo real, tal como es desarrollado aquí por Lacan, sería lo que en el discurso de la lógica se ubica como imposible, y por esto la lógica se definiría como la ciencia de lo real. En este sentido tanto la ciencia moderna como el psicoanálisis (desde Lacan) operarían a partir de una noción de real semejante, incluso aunque el científico la desconozca. ${ }^{11}$ Lo real lacaniano no sería un núcleo duro inaccesible, una suerte de «cosa en sí» kantiana; está vaciado de trascendencia, positividad y ontología (Žižek 1992, p.225). Se trata de un real, en tanto resto, producto de la propia estructura simbólica, creado en el propio fracaso de la escritura, en los propios impasses de la formalización; al decir de Lacan: «Lo real no puede inscribirse sino con un impase de la formalización» (2011b, p.112). ${ }^{12} \mathrm{Al}$ depender de la lógica, lo real puede cambiar (ya que la lógica como tal, es incompleta); lo que es imposible en un sistema lógico, no lo es en otro. ${ }^{13}$ Por tal motivo lo real lacaniano no es trascendente, sino inmanente al lenguaje: «La estructura es lo real que sale a relucir en el lenguaje» (Lacan, 2012a, p.500); se trata de un real que no se capta por la experiencia, ya que para Lacan la estructura es «lo que no se aprende de la practica» (Ibídem, p.485). ${ }^{14}$

Muchos grandes descubrimientos y avances de la ciencia se dan por azar, o por error, ya que en el momento que aparece la dimensión de lo imposible, algo de lo real se puede aprehender. Algo de lo real se puede captar cuando cesa de no escribirse, que es la fórmula que Lacan da de lo contingente (2011b, p.113). Y si se siguen los planteos de Milner de que «La estructura de la ciencia moderna se apoya enteramente sobre la contingencia» (op. cit., p.65), no hay ciencia que no sea ciencia de lo contingente. En este sentido, los planteos de Milner apuntan a mostrar que en cierto punto Lacan es popperiano. Según Popper cualquier proposición de la ciencia debe poder ser refutable, pero como plantea Milner

«una proposición sólo puede ser refutable si su negación no es lógicamente contradictoria o no es materialmente invalidada por una observación simple (...),

11 No es condición necesaria que el científico, al hacer ciencia, sepa que es lo que hace, ni sobre que concepciones se apoya para operar.

12 Los progresos significativos de la ciencia, vinculados a los cambios de paradigma, ocurren a partir de «impasses en la formalización».

13 A modo de ejemplo, lo que es imposible en la mecánica newtoniana (a saber, el tiempo y el espacio relativos) no lo es en la teoría de la relatividad de Einstein. De la misma forma, lo que es imposible en la teoría de la relatividad de Einstein (superar la velocidad de la luz), no lo es en la mecánica de Newton.

14 Para Lacan, el «matema» es lo único que puede enseñarse, y sin recurrir a ninguna experiencia sensible, ya que incluso la experiencia está fundada en un discurso, y las locuciones que permite no apuntan sino a establecerlo (Lacan 2012a, p.496). 
su referente debe poder-lógica o matemáticamente- ser diferente de lo que es» (Ibídem, p.63).

Esto no sería otra cosa que la contingencia, es decir aquello que no es necesario, que puede ser diferente de lo que es: «sólo una proposición contingente es refutable» (Ibídem, p.63).

Si para Lacan lo real es lo imposible, es decir lo que no cesa de no escribirse (2011b, p.114), es justamente en el momento de que algo cesa de no escribirse, en la contingencia, que se toca algo de lo real. ${ }^{15}$ Pero lo que la ciencia capta de lo real, lo contingente, solo puede ser diferente de lo que es en el momento antes de escribirse, «en el instante ulterior, la letra lo fijó como es y como no pudiendo ser diferente de lo que es, salvo cambiando la letra» (Milner op. cit., p.65). Una vez escrito no puede ser diferente de lo que es, es decir que se hace necesario, cuya fórmula para Lacan (2011b, p.114) es lo que no cesa de escribirse. ${ }^{16}$ Esa es la naturaleza de las leyes de la ciencia; son necesarias, hasta que surja nuevamente la irrupción de lo imposible/contingente. ${ }^{17}$ En ese momento se puede cambiar la letra, se puede escribir algo distinto. Milner plantea siguiendo la doctrina de Lacan que «una vez fijada la letra, solo permanece la necesidad e impone el olvido de la contingencia que la autorizó» (op cit., p.67). Esto está en relación al planteo de Lacan acerca de que «la ciencia, si se mira con cuidado, no tiene memoria. Olvida las peripecias de las que ha nacido, cuando está constituida» (2002a, p.826).$^{18}$ Este olvido es justamente para Milner, la forclusión del sujeto. El sujeto sería para él lo que emerge entre el instante anterior a la escritura y el instante posterior, es decir, lo que emerge en el momento de la pura contingencia (op. cit., p.66). Para seguir la argumentación realizada anteriormente sobre la forclusión de la verdad en la ciencia, deberíamos cambiar, en el párrafo anterior, sujeto por verdad: la verdad sería lo que emerge entre el instante anterior a la escritura y el instante posterior.

Milán (2007) hace una crítica a cierto aspecto de este desarrollo de Milner. Según él, la contingencia desde el punto de vista del psicoanálisis no admite ser

15 Guitart, para el campo de la matemática, lo explica de la siguiente forma: «puede suceder que, en el trabajo de copia y reescritura sobre o con un objeto matemático, se alcance un punto de tope, es decir, algo que, con los medios expresivos puestos en práctica, no pueda escribirse; o sea, un punto de imposible (...). La reabsorción de esta falta es entonces un segundo trabajo (...), para reformar el sistema mismo de escritura y producir un nuevo estilo de cálculo en el cual eso se escribirá» (op. cit., p.134-135).

16 «la categoría en la cual el objeto adquiere entonces sentido para la acción es totalmente contingente en su emergencia, pero de esa manera, no obstante, se inscribe la necesidad» (Guitart op. cit., p.129).

17 Se trata de una necesidad retroactiva.

18 Como dice Guitart, «el uso de un objeto matemático supone una borradura de su fundación como tal» (op. cit., p.129). 
reducida a la finitud del cálculo lógico, y por lo tanto no es compatible con el dispositivo de refutabilidad de Popper. En el desarrollo de Milner lo contingente se confunde en algunos momentos con lo posible, y es en este punto donde aparece más nítidamente el carácter «cientificista» de la lectura que Milner realiza de la contingencia. Según Milán, la inclusión de lo contingente dentro del cálculo, su reducción a lo posible, es el núcleo mismo del intento de sutura del sujeto por la ciencia, por la propia estructura de la escritura científica, que es la escritura lógico-matemática. Es una sutura, dice Milán, del «sujeto-contingencial». Este sujeto-contingencial, no puede estar dentro del cálculo, dentro de la finitud de las posibilidades. Justamente aparece, como se mencionó, en lo no calculable, y Milán plantea que precisamente surge en el choque entre lo imposible y lo contingente. Lo contingente, entendido así, no se trata de un acontecimiento improbable (que es en realidad posible, que estaba dentro de las posibilidades), sino de un acontecimiento imposible (lo real lacaniano). «Se toca un real» cuando algo que no cesa de no escribirse (lo imposible), precisamente cesa de no escribirse (lo contingente). Habría, según Milán, una diferencia de lectura sobre lo contingente y sobre lo imposible, es decir sobre lo real, en la ciencia y en el psicoanálisis, que radica en la diferencia entre la escritura científica y la escritura del psicoanálisis. Lo real para la ciencia sería totalmente calculable, mientras que lo real psicoanalítico, es decir lo real del sujeto, sería siempre imposible, imposible de captarse totalmente a través de lo simbólico, por lo que cuando irrumpe, lo hace de forma inesperada, «violenta». Desde el psicoanálisis, a diferencia de la ciencia, lo contingente aparecería «no-todo» dentro de las posibilidades, y por tanto sería incalculable. Respecto a la distinción entre lo posible y lo contingente, Žižek dice que:

«lo contingente, (...) no es en modo alguno igual a lo posible: en la contingencia hay siempre algo de 'encuentro con lo Real', algo de la violenta emergencia de una entidad absolutamente nueva que desafía los límites del campo establecido de lo que uno sostiene como 'posible'. Y 'lo posible' es, por así decirlo, una contingencia ‘domesticada’» (1998, pp.255-256).

\section{Consideraciones FINALES}

Milner afirma que Lacan se separa de Freud en lo que refiere al ideal de la ciencia, ya que el primero, no creería para nada en él, o mejor dicho no creería en él para el psicoanálisis (op.cit., p.38). La ciencia para Lacan no sería entonces un punto ideal, que el psicoanálisis debería en algún momento alcanzar, o hacía el que debería tender, $\mathrm{y}$ «dado que no hay un ideal de la ciencia en lo tocante al psicoanálisis, tampoco existe para él una ciencia ideal. El psicoanálisis encontrará en sí mismo los fundamentos de sus principios y sus métodos» (Milner op. 
cit., p.39). En este sentido el psicoanálisis tampoco debería tomar prestado los modelos de las ciencias existentes, sean estas las ciencias de la naturaleza, las ciencias sociales o las llamadas ciencias humanas. Sin embargo estos planteos de Milner pueden ser puestos en cuestión. Cabe recordar la aspiración de Lacan de alcanzar cierta formalización matemática para el psicoanálisis (2011b,p.144). Son muchas las referencias lacanianas que apuntan en este sentido, así como sus propias teorizaciones a partir de elaboraciones matemáticas (topología, teoría de conjuntos, teoría de nudos, lógica simbólica, teoría de juegos, aritmética, etc.). Justamente, Lacan comenta que lo que lo empuja a la elaboración de una nueva noción de sujeto en psicoanálisis es «una carencia de la teoría sumada a un numero de abusos en su trasmisión, que, por no carecer de peligro para la praxis misma, resultan tanto la una como los otros en una ausencia total de estatuto científico» (2002c, p.756). De esta forma, no se puede afirmar que la ciencia no suponga para Lacan un punto ideal, o una referencia fundamental. Asimismo, no se puede decir, al menos sin equivocarse, que con Lacan el psicoanálisis no debería tomar presentado modelos de otras ciencias. Basta recordar la forma en que utiliza la lingüística, la matemática, la etología, la lógica, la antropología, etc. Si bien no se trata de una adaptación de estas disciplinas al psicoanálisis (ya que en el mismo acto de tomarlas como «modelo» son subvertidas) el psicoanálisis no permanece ajeno a ellas.

¿Es el psicoanálisis finalmente una ciencia? ¿Podría llegar a serlo? En este punto es pertinente introducir el viraje de la pregunta lacaniana sobre la cientificidad del psicoanálisis. Esta pregunta es «la que va de: ¿el psicoanálisis es una ciencia? a: ¿qué es una ciencia que incluya el psicoanálisis?» (Lacan 2012c, p.205). Es una pregunta que no apunta al problema de decidir si el psicoanálisis es, o debería ser, una ciencia, sino a la pregunta de si es posible hacer una ciencia que incluya al psicoanálisis; es decir una ciencia que restituya la dimensión de la verdad, dimensión de la cual la ciencia moderna no-querría-saber-nada. Incluso, en este punto, podría considerarse el psicoanálisis justamente como aquella ciencia que restituye en su campo, la función de la verdad, que atiende específicamente la división del sujeto entre saber y verdad.

Si se acepta la premisa lacaniana, de que el sujeto sobre el que opera el psicoanálisis es el sujeto de la ciencia, y que el psicoanálisis es sincrónico a la ciencia moderna, la relación entre psicoanálisis y ciencia se vuelve extremadamente compleja. Tal vez, como plantea Dunker (op. cit., p.314), el psicoanálisis esté no-todo en la ciencia, e inversamente, su existencia no pueda ser sin la ciencia.

Lacan establece el campo del psicoanálisis en una relación sincrónica a la ciencia moderna, y al mismo tiempo determina la frontera entre ambos tipos de saber. El psicoanálisis no subvierte únicamente la clínica médica, sino que subvierte a la propia ciencia, ya que opera con su propio sujeto, con la división 
de ese sujeto (división que la ciencia se esfuerza por suturar). En este sentido, el psicoanálisis operaría en relación al sujeto, de forma inversa a la ciencia. Mientras esta última se constituye en el esfuerzo por suturar la división del sujeto entre saber y verdad, el psicoanálisis atiende específicamente esta división. De esta forma se entiende que el psicoanálisis no puede ser sin la ciencia.

No hay posibilidad de que la experiencia freudiana haya surgido fuera del ámbito de la ciencia, en el sentido moderno. Las histéricas que acudían a Freud a finales del siglo XIX, buscaban el alivio de su malestar, de su sufrimiento y de su síntoma, en la ciencia, representada allí por la medicina: «la aprehensión correcta de la verdadera naturaleza de los fenómenos histéricos se inscribe dentro de los progresos del conocimiento neurológico, fisiológico y patológico, y (...) por lo tanto el saber médico fue la condición de posibilidad del psicoanálisis» (Bercherie 1988, p.278). Es por los impasses de la ciencia - por ejemplo, del saber médico-, por sus fracasos, por donde surge el psicoanálisis. Y esto porque el psicoanálisis opera con el «desecho» de la ciencia, porque se ocupa precisamente de lo que no anda en ella. Si el psicoanálisis tiene lugar, es porque a la ciencia «le sobrevive la neurosis» (Lacan 2012a, p.477).

\section{REFERENCIAS BIBLIOGRÁFICAS}

AMIGO, S. (2009). El psicoanálisis y las ciencias, los científicos, los matemáticos, los lógicos. En Jacques Lacan y los matemáticos, los lógicos y los científicos. Buenos Aires: Escuela Freudiana de Buenos Aires.

AMSTER, P. (2010). Apuntes matemáticos para leer a Lacan. 2. Lógica y Teoría de Conjuntos. Buenos Aires: Letra Viva.

BACHELARD, G. (1991). La formación del espíritu científico. Contribución a un psicoanálisis del conocimiento objetivo. Mexico, D.F.: Siglo Veintiuno Editores S.A.

BERCHERIE, P. (1988). Génesis de los conceptos freudianos. Buenos Aires: Editorial Paidós.

CASSIN, B. (2013). Jacques el sofista. Lacan, logos y psicoanálisis. Buenos Aires: Manantial.

DESCARTES, R. (2004a). Discurso del método. Caronte Filosofía. La Plata: Terramar Ediciones.

- - , (2004b). Meditaciones metafísicas. Caronte Filosofía. La Plata: Terramar Ediciones.

DUNKER, C. (2011). Estrutura e constituição da clínica psicanalítica. Uma arqueologia das práticas de cura, psicoterapia e tratamento. São Paulo: Annablume editora. 
Psicoanálisis y Ciencia...

EIDELSZTEIN, A. (2012). Las estructuras clínicas a partir de Lacan. 1. Intervalo y holofrase, locura, psicosis, psicosomática y debilidad mental. Buenos Aires: Letra Viva.

- - , (2015). Otro Lacan. Estudio crítico sobre los fundamentos del psicoanálisis lacaniano. Buenos Aires: Letra Viva.

EINSTEIN, A. (2005). Así lo veo yo. Buenos Aires: Longseller.

GUITART, R. (2003). Evidencia y extrañeza. Matemática, psicoanálisis, Descartes y Freud. Buenos Aires: Amorrortu editores S.A.

JULIEN, P. (2012). Psicosis, perversión, neurosis. Buenos Aires: Amorrortu editores S.A.

KOYRÉ, A. (2007). Estudios de historia del pensamiento científico. Mexico, D.F.: Siglo Veintiuno Editores S.A.

KUHN, T. (2013). La estructura de las revoluciones científicas. Mexico, D.F.: Fondo de Cultura Económica.

LACAN, J. (1987). El Seminario de Jacques Lacan. Libro 11: Los Cuatro Conceptos Fundamentales del Psicoanálisis. Buenos Aires: Editorial Paidós.

_-_, (1992). El Seminario de Jacques Lacan. Libro 7: La Ética del Psicoanálisis. Buenos Aires: Editorial Paidós.

- - , (1999). El Seminario de Jacques Lacan. Libro 5: Las Formaciones del Inconciente. Buenos Aires: Editorial Paidós.

- - _. (2002a). La ciencia y la verdad. En Escritos 2. Buenos Aires: Siglo Veintiuno Editores S.A.

- - - (2002b). La instancia de la letra en el inconciente o la razón desde Freud. En Escritos 1. Buenos Aires: Siglo Veintiuno Editores S.A.

- - - , (2002c). Subversión del sujeto y dialéctica del deseo en el inconsciente freudiano. En Escritos 2. Buenos Aires: Siglo Veintiuno Editores S.A.

- - , (2010). La tercera. En Intervenciones y Textos 2. Buenos Aires: Manantial.

- - - (2011a). El Seminario de Jacques Lacan. Libro 18: De un discurso que no fuera del semblante. Buenos Aires: Editorial Paidós.

-_-, (2011b). El Seminario de Jacques Lacan. Libro 20: Aun. Buenos Aires: Editorial Paidós.

-_-, (2011c). El Seminario de Jacques Lacan. Libro 3: Las Psicosis. Buenos Aires: Editorial Paidós.

- - - (2011d). El Seminario de Jacques Lacan. Libro 4: La Relación de Objeto. Buenos Aires: Editorial Paidós.

_- -, (2012a). El atolondradicho. En Otros escritos. Buenos Aires: Editorial Paidós. 
- - , (2012b). El Seminario de Jacques Lacan. Libro 23: El sinthome. Buenos Aires: Editorial Paidós.

- - - , (2012c). Los cuatro conceptos fundamentales del psicoanálisis. Reseña del Seminario de 1964. En Otros escritos. Buenos Aires: Editorial Paidós.

LE GAUFEY, G. (2010). El sujeto según Lacan. Buenos Aires: El cuento de la plata S.R.L.

- - - (2012). La incompletud de lo simbólico. Buenos Aires: Letra Viva. Ediciones LECOL.

MILÁN-RAMOS, J. . (2007). Passar pelo escrito. Campinas: Mercado de Letras.

MILNER, J. C. (1996). La obra clara. Buenos Aires: Manantial.

POPPER, K. (2008). La lógica de la investigación científica. Madrid: Editorial Tecnos.

PORGE, E. (2007). Trasmitir la clínica psicoanalítica. Freud, Lacan, hoy. Buenos Aires: Nueva Visión.

ŽIŽEK, S. (1992). El sublime objeto de la ideología. Buenos Aires: Siglo Veintiuno Editores S.A.

- - , (1998). Porque no saben lo que hacen. El goce como un factor político. Buenos Aires: Editorial Paidós.

Gonzalo Grau Pérez Licenciado en Psicología y maestrando en Psicología Clínica (Universidad de la República).

Lineas de Investigación:

Integrante del grupo de investigación «Formación de la clínica psicoanalítica en el Uruguay» (Facultad de Psicología, Universidad de la República, Uruguay) coordinado por el Prof.Agdo. Dr. Guillermo Milán. Responsable de la línea de investigación «Recepción de Lacan en Uruguay».

Publicaciones recientes:

- Grau Pérez, G., Milán-Ramos, G.(2016). La transferencia citada textualmente. En Prática da letra, uso do inconsciente, 271-285. Mercado de Letras: Campinas. ISBN: 978-85-7591-461-8.

-Grau Pérez, G. (2015). La experiencia de la palabra en el Psicoanálisis. Tábano, 11, 53-59. ISSN: 1852-7221.

Correo electrónico: gongrau@gmail.com 